\title{
Axiography and MRI in the diagnosis of temporomandibular joint pathology
}

\author{
M. G. Piancino ${ }^{1}$, S. Cirillo², G. Frongia' ${ }^{1}$, F. Cena ${ }^{1}$, A. A. Bracco ${ }^{1}$, P. Bracco ${ }^{1}$ \\ ${ }^{1}$ Department of Orthodontics and Gnathology (Masticatory Function), School of Orthodontics and Gnathology, \\ University of Turin - Dental School, Torino, Italy \\ ${ }^{2}$ Unit of Radiology, Institute for Research and Treatment for Cancer, Candiolo, Italy
}

Received December 15, 2008; Accepted February 2, 2009

Aim of the study was to compare the Magnetic Resonance Imaging (MRI) and the Computerized Axiography tracings to find out the agreement of the two exams. The results showed that the agreement was very low. MRI and Computerized Axiography record different characteristics of the joints being the MRI a static and the Axiography a dynamic exam. They should be considered complementary and both necessary for a full diagnosis of Temporo-Mandibular Joint Pathology.

Keywords: Magnetic resonance imaging, axiography, temporomandibular joint, temporomandibular disorders, temporomandibular diagnosis

It has been a great honour receiving the prize for the best basic research poster at the IAAID congress "Consensus Conference - from diagnosis to treatment”, 25th - 28th October, Krems, Austria. According to the philosophy of our school, from a long time, we study both anatomy and function of TMJ using different instruments and protocols. The data are recorded by different group of operators, specialized in different fields, but the diagnosis is interdisciplinary.

Using always Axiography and MRI to diagnose the TMD patients, we realized that those two exams are necessary for a full diagnosis of the TMJ pathology [1-3].

The MRI shows the anatomy of the soft and hard tissues of the TMJ; but, to obtain high-resolution images, the joint must be completely static, any movement meaning a blurred image. On the contrary, the axiography shows the functional aspect of the joint during border movements and, eventually, the functional compensation to the altered anatomy [4].

This is a very important difference between the two exams and, for this reason, specificity or sensitivity may result very low.

Correspondence: Pietro Bracco, Department of Orthodontics and Gnathology, University of Turin - Dental School, Via Nizza 230, 10126 Torino, Italy.

E-mail: pietro.bracco@unito.it
Tab. 1: The table shows the Kappa Index of $13 \%$ meaning a level of agreement between MRI and Axiography weak/decent

RM

\begin{tabular}{r|rrr|r} 
& \multicolumn{5}{|c}{ AxIO } & 2 & TOT \\
\hline & 0 & 1 & 7 & 98 \\
0 & 64 & 27 & 7 & 66 \\
1 & 36 & 23 & 12 & 44 \\
2 & 25 & 7 & 26 & 208
\end{tabular}

$\begin{array}{crcccc}\text { Agreement } & \text { expected } & \text { kappa } & \text { Std. Err. } & z & \text { prob }>z \\ 78.57 \% & 72.13 \% & 0,1315 & 0.0653 & 3.54 & 0.0002\end{array}$

The aim of this study was to evaluate the agreement of MRI diagnostics imaging and axiographic tracings to establish if they give the same diagnosis or if they detect different aspects of the TMJ pathology.

One hundred and five patients suffering from TMD, aged 16-50 years (mean age: 33 years) were selected for this studyfrom the 1st June 1998 through the 1st December 2003 from among those referred to the Department of Orthodontics, University of Turin, Italy.

All subjects underwent magnetic resonance imaging (MRI) (Signa GE Medical Systems) and computerized axiography (Cadiax ${ }^{\circledR}$ Diagnostic axiograph and Gamma Dental Software, Gamma Dental) after clinical evaluation.

The results showed that the agreement of the two exams is low (Tab. 1). The Kappa Index was $13 \%$ and the level of agreement was weak/decent.

This result may be due to the fact that axiography shows a functional aspect or a functional compensation, during border movements, while MRI shows the TMJ anatomy in static conditions. The function of the TMJ is very important and the dentists need to know both the anatomy and the function of the TMJ before any therapeutic decision; but the dynamic aspect alone is not enough, and it is important to know the anatomic situation contemporary. The functional aspect re- 
presents the actual working capability of the TMJ, while the anatomy, when functionally compensated, may represent the future risks of worsening of the symptoms.

Those two exams should be considered complementary and not in agreement or in disagreement.

It would be a desirable progress, in the near future, to have the real dynamic MRI recording of the movements of the condyles to record contemporary function and anatomy and to demostrate the smoothness of the condylar pattern.

We would like to thank the scientific commitee of the IAAID congress for the appraisal of our work.

\section{References}

[1] Piehslinger E, Schimmerl S, Celar A, et al. Comparison of magnetic resonance tomography with computerized axiography in diagnosis of temporomandibular joint disorders. Int J Oral Maxillofac Surg 1995;24:13-9.

[2] Parlett K, Paesani D, Tallents RH, et al. Temporomandibular joint axiography and MRI findings: A comparative study. J Prosthet Dent 1993;70:521-31.

[3] Georges Rozencweig. Èvaluation comparative de deux moyens d'investigation des dysfonctions cranio-mandibulaires: l'Axiographie et l'Imagerie en Rèsonance Magnètique. Rev Ortop Dento Faciale 1991;25:205-13.

[4] Piancino MG, Roberi L, Frongia G, et al. Computerized axiography in TMD patients before and after therapy with "function generating bites". JOR 2008;35:88-94 